\title{
Health evaluation of EV business ecosystem based on projection pursuit and an improved matter-element extension combined with TOPSIS
}

\author{
Shuyu Dai, a ${ }^{1,}$ Xin Li ${ }^{2, b}$, Dongxiao Niü,c, Guangsheng Zhan ${ }^{2, d}$ \\ and Yuan Zhang ${ }^{2, e}$ \\ ${ }^{1}$ School of Economics and Management, North China Electric Power University, Changping Beijing, \\ 102206, China \\ 2 State Grid Energy Research Institute, Changping Beijing 102209, China \\ aDaiShuyu@ncepu.edu.cn, bnyy_lixin@163.com, 'niudx@ncepu.edu.cn, \\ dnyy_zgs@163.com, enyy_zhangyuan@126.com
}

\begin{abstract}
Keywords: Health evaluation; EV business ecosystem; Project pursuit; Matter-element extension; TOPSIS.

Abstract. Since the number of electric vehicles is increasing rapidly, there is urgent need to nurture this emerging industry's business ecosystem. The livelihood of an EV business ecosystem is important to different ecosystem participants: industrial participants, government agencies, industry associations, customers, and other relevant stakeholders, all these participants want to know whether their ecosystem is healthy and performing well. However, there exists no research focusing on the health of EV business ecosystem as health is typically regarded from a project scope. This paper proposed the concept of EV business ecosystem health degree based on the theory of business ecosystem and the evaluation of its health. A four-layer index system is developed from aspects of system coordination, system functionality and system suitability. An improved matter-element extension model combined with TOPSIS is constructed to assess the health status of the EV business ecosystem. The weight of each indicator is calculated using the projection pursuit which is optimized by firefly algorithm (FA). Furthermore, the closeness and characteristic value are calculated to grade the EV business ecosystem health. Finally, the EV business ecosystem in Beijing is taken as an example to confirm the operability and effectiveness of the proposed evaluation index system and model. It is testified that the projection pursuit and an improved matter-element extension combined with TOPSIS model outperforms in reflecting actual condition and can be applied to EV business ecosystem health assessment.
\end{abstract}

\section{Introduction}

With the rapid development of urbanization and a boom in automobile industry, environment concerns over climate change and energy problems, especially sharp rising oil price push forward the emergence of electric vehicle (EV) industry [1]. Faced with the technical difficulties, market uncertainty and weak industry system [2], a pressing matter of the moment is exploring how to realize the specialization and general adoption of market principle. Business model innovation is an important means to make the rapid expansion come true. The concept of business ecosystem provides a new angle of view, which would help nurture and construct a friendly and healthy stakeholder network in the emerging industry [3-4].

In recent years, many scholars and economists have turned their attention from the performance of individual firms to the growth of business ecosystem-based strategies [5-6]. Compared to traditional supply chain, the business ecosystem contains more members such as suppliers, partners, customers, and other stakeholders like government, labor union, universities and industry associations [7-10]. All system participants contributes their complementary resources and capabilities to establish a sustainable business ecosystem. Unlike the conglomerate-driven or development-oriented strategies, the ecosystem-based strategy furnishes enterprises with a more innovative and overall viewpoint of cross-industry cooperation and co-evolution [9]. Within the emerging industry's business ecosystem, 
those different stakeholders make self-decision and interactions with other system actors as well as the environment [11].

EV industry, as an emerging industry, has broad market prospects and constantly room for improvement because EVs are expected to become the trend of modern cars as their obvious characters like excellent performance, saving energy, protecting environment and proper price. Although this industry develops rapidly over recent years, it is still confronted with difficulties in perfecting the structure and encouraging those stakeholders to achieve collaborative innovation for securing a well business mode [12-13]. From both theoretical and practical aspects, it is critical moment to nurture business ecosystem of EV industry. The Chinese government has attached great importance to the development of EVs since several research and development (R\&D) projects and the national " 863 program" which established a number of national key scientific research programs were launched in 2001[14]. During the Tenth Five-Year Plan period, "three vertical three horizontal" development strategy was established and came into demonstration operation in the Tenth Five-Year Plan later period. Then the EV industry with strong potential for industrialization is ranked as one of the seven strategic emerging industries during the next Five-Year Plan period. It is evident that China vigorously promotes the expansion of EVs and has made some achievements. All these lay the foundation for the industrialization and commercialization of the EV industry. However, there are still certain bottlenecks i.e. lacking supporting policy, infrastructure construction, local protection and consumer subsidies, not well established mechanism of profit distribution, low R\&D capability of the industrial players, which hinder the course of industrialization [14]. Consequently, it is necessary to explore this EV industry evolution through employing the business ecosystem framework. Despite a growing literature on the electric vehicle industry evolution through the nurturing of its ecosystem, there is still limited research about quantitative assessment model for taxi industry from the scope of business ecosystem's health.

Against this backdrop, in order to prompt a feasible and effective method of health evaluation in EV business ecosystem, this paper first established the indicator system based on major characteristics of EV industry. Then an improved matter-element extension model combined with TOPSIS is constructed to assess the health condition of the EV business ecosystem. Finally, taking the EV ecosystem in Beijing as a case study, the empirical analysis results showed that this model is valid and practicable. The rest construction of the paper is as follows: Section 2 is the literature reviews; Section 3 discusses the concept of EV business ecosystem health and the design of the index system; Section 4 describes proposed model; Section 5 conducts a case study; Section 6 shows the conclusions.

\section{Literature Reviews}

EV business ecosystem. There is substantial literature concentrating on the business ecosystem. Since the 1990s, the notion of business ecosystem was proposed by Moore to explicate the uncertain commercial environment by demonstrating biological ecosystems as an analogy. Moore defined the business ecosystem as "an economic community, consisting of different levels of organizations and individuals such as suppliers, lead producers, competitors and other stakeholders, which produces good and services of value to customers, who themselves are members of the ecosystem" [8]. This concept emphasizes the importance of co-evolution and interaction among these organizations. After Moore, many scholars have the deepest commitment to research in this field of investigation. The main points of these studies can be generalized into three aspects, i.e. circumscribing the business ecosystem and depicting it framing, exploring operational models or competitive strategies, introducing the cases of business ecosystem in several areas [15-19].

The fast development and arising promise of EV industry are concretized by fierce competition between vehicles with internal combustion engines and those with electrical engines [20]. Bohnsack et al. studied the EV business ecosystem from the aspect of business model [21]. They investigated what effects would been made on the evolution of business models for EVs by incumbent and 
entrepreneurial firms' path dependencies. Through a qualitative analysis, it was evident that incumbent and entrepreneurial firms approach business model innovation in different ways. Substantial qualitative cross-case studies have been conducted in the emerging EV industry from the perspective of business ecosystem. It is confirmed that EV industry could give an illustration of typical characteristics of business ecosystems. Furthermore, since there are different types of car firms, which provides the possibility to research the diversification of business ecosystem structure and operating mechanism. The EV business ecosystem comprises different levels of organization including industrial participants, government agencies, industry associations, customers, and other relevant stakeholders. Inter-organizational and cross-industry collaborations, among these EV industry players, promote the formation and development of ecosystem. Shang and Shi [1] demonstrated a value stream in EV business ecosystem. This might be interpreted that the supply side is associated with the production encompassing original equipment manufacturers (OEM), battery manufacturers and electronic control systems, while the demand side is occupied by end-users and incentivizing plans. Then the supply and demand are integrated by interface. The supporting participants provide the system with infrastructure development, adapted industrial policies, legislations and standards. Iansiti and Levien classified firms in business ecosystems into keystones, which own and shape the ecosystem, niche players, and dominators [3]. From this point of view, Galateanu and Avasilcai aimed to emphasize the importance of business ecosystems' actors in terms of their competitive behavior and illustrated the linkage between the adopted strategy and the actors' performance within the automotive business ecosystem. Most importantly, they found that a company within EV industry can change its behavior according to market or ecosystem' evolution through performing an analysis, which pointed out the future research direction. In order to explore the structure. Operating mechanisms and integrated models of EV business ecosystem, multiple case studies of EV producers was examined by Rong et al. [22]. They classified the EV ecosystem into four paradigms according to a target market and growth context and explored three key operating mechanisms with which to organize EV business ecosystems, i.e. vision developing, platform organizing and institution re-configuring. As systematic research on the business ecosystem of emerging industries from the perspective of different stakeholder roles' transformation is in blank condition almost, Lu et al. established a theoretical framework from three aspects namely stages of business ecosystem lifecycle, stakeholder classification and functional roles, to explore how they interact with each other and contribute to the evolution of the EV industry [14]. Currently, the Chinese EV industry has entered a period of industrial development.

Business Ecosystem Health Assessment. Just as natural ecosystem, the actions of a company can affect the health of the entire business ecosystem in varying degrees, which in turn will affect the performance of the company. Business ecosystem health is not only related to the strategic choice of the existing enterprises, but also related to the selection of the ecosystem which made by potential members. All these are based on the objective and fair evaluation on business ecosystem health, hence, it is of practical significance to assess the health of their business ecosystem in varied and complex environments.

Since the business ecosystem is very complex and influenced by multi-dimensionally associated factors, there have always been disagreements on evaluating system health. Iansiti and Levien [3] stride the first step to probe into the business ecosystem health. They didn't give an exact definition, instead, they introduced "health" as an overall performance indicator of business ecosystems and put forward three parameters to examine the fitness level, namely productivity, robustness and niche creation. Specifically speaking, productivity is asserted as the efficiency with which an ecosystem transforms inputs into lower costs and innovative products. Robustness refers to the capability of an ecosystem to face and survive perturbations and disruptions. Niche creation, representing the capacity to create meaningful diversity and thereby novel capabilities, can be evaluated from the aspects of variety and value creation. Obviously, Iansiti and Levien classified business ecosystem health from the analogy with biological ecosystems. den Hartigh et al. [23] developed a concrete measurement tool containing two perspective: partner health and network health, the former is to reflect the 
financial well-being when the latter is to reflect the network strength. Hu et al. [24] defined business ecosystem health as the capability to create valuable products and services efficiently and continuously. They elaborated on five attributes i.e. logical community structure, favorable non-physical environment, efficient system productivity, sustainability and coordination of management mechanism. According to Zhang [25], when a business ecosystem is in healthy condition, it means that when facing external heavy pressure, the ecosystem can still sustain stability and develop continuously. Then an index system with 8 indicators was proposed based on dynamics, levels, creativity, pertinence and cumulative vulnerability of ecological theory. Li [26] divided the overall performance index of business ecosystem be into power performance, inclusiveness and robustness. By analyzing the connotation and measurement scale of business ecosystem health, Li et al. [27] analyzed the basic attributes of business ecosystem from five aspects: ecological attributes, structure attributes, functional attributes, operation mechanism attributes and lifecycle attributes. Additional, Analytic Hierachy Process (AHP) and the Fuzzy Comprehensive Evaluation Method were employed to evaluate Information Technology Business Ecosystem Health in China. A four-layer index set was developed from aspects of robustness, productivity and sustainability to assess the taxi industry ecosystem health by Zhang and Zhong [28]. Though domestic and foreign scholars hold different conceptions and evaluating indicators, these research findings have certainly led to a greater understanding of business ecosystem health and completion of its index system.

In the context of EV business ecosystem health, literature on definition and evaluation is still in its infancy. Zubaryeva A et al. [29] presented a modeling approach which was based on a combination of five selected criteria groups named demography, environment, economy, energy and transport. However, this investigation was fixed on the on the identification of potential lead markets for EVs in Europe. To the best of our knowledge, there is little research focusing on evaluating the performance of EV industry from the scope of business ecosystem health. To bridge the gap in existing studies, this paper is intended to make up for the research flaws. Based on a review of literature and expert consultation, as well as considering the structure and characteristics of EV business ecosystem, an evaluating framework of overall performance is put forward. This paper proposed the concept of EV business ecosystem health degree and constructed an index system. The weight of each indicator is calculated using the projection pursuit which is optimized by firefly algorithm (FA). Furthermore, an improved matter-element extension model combined with TOPSIS is constructed to assess the health status of the EV business ecosystem.

\section{EV Business Ecosystem Health Degree and Indicator System}

EV Business Ecosystem Health Degree. Chinese electric vehicle industry developing path can be divided into three stages, namely industrial germination period, industrial incubation period, and industrial development period. An EV business ecosystem is supposed to be a sustainable economic community with key stakeholders include vehicle manufacturers, infrastructure construction operators, key parts manufacturers, EV operating companies and consumers (public and private) as well as the government, entering into the ecosystem in distinct period and displaying vital roles. As described in the literature review, previous research on EV business ecosystem focused on diverse perspectives. Although insightful, studies focused on how to effectively evaluate its overall performance are insufficient, thus obstructing exploration into the operating mechanism to improve the overall efficiency of the system. The EV industry's capability to survive and grow relies on multi-facet performance indicators, which requires a clear definition of the ecosystem main goal [30]. Based on the business ecosystem's health theory, a healthy EV ecosystem refers to be in good operating condition with stability, continuity as well as the ability to maintain its organization, self-adjust and adapt to the environment. The degree of ecosystem health is mainly affected by the coordination among system members, the function of the system and the adaptability to the external environment. 
Evaluation Indicator System for EV Ecosystem Health. The EV ecosystem health indicators is selected and designed for the purpose of reflecting the performance of the EV ecosystem through data analysis, monitoring trends over time and diagnosing the causes of existing problems. In the matter of a company who is in the business ecosystem, the starting point of value analysis should be extended from the internal to the external environment. In other words, enterprises should not be confined to their own interests, instead, they should pay attention to the cooperation with external partners, provide more valuable products and services to users, ensuring the sustainable development of entire external environment. As for the EV business ecosystem, it is necessary not only to focus on maximizing the whole value of the system, but also to consider the particularity of the industry. To begin with, as a member of the system - - power enterprises undertake important social responsibilities, hence, users and other members of society should be taken into account in the evaluation. Secondly, under the trend of global energy saving and environmental protection, companies need to keep an eye on the impact of their actions on the environment. As EVs are products of science and technology dealing with energy and environmental pollution, environmental factors should be included in the assessment of ecosystem health.

Combined with the business ecosystem health evaluation theory, the influence factors include system coordination among the members, system functionality and system adaptability to the environment etc. Coordination reflects the planning mechanism, interest balance and value consensus of the system. Functionality reflexes the resource allocation ability and operation efficiency of the system. Suitability mainly reflects the adaptability and change ability of the system to external factors. The EV business ecosystem health assessment index system is shown in Fig.1. 


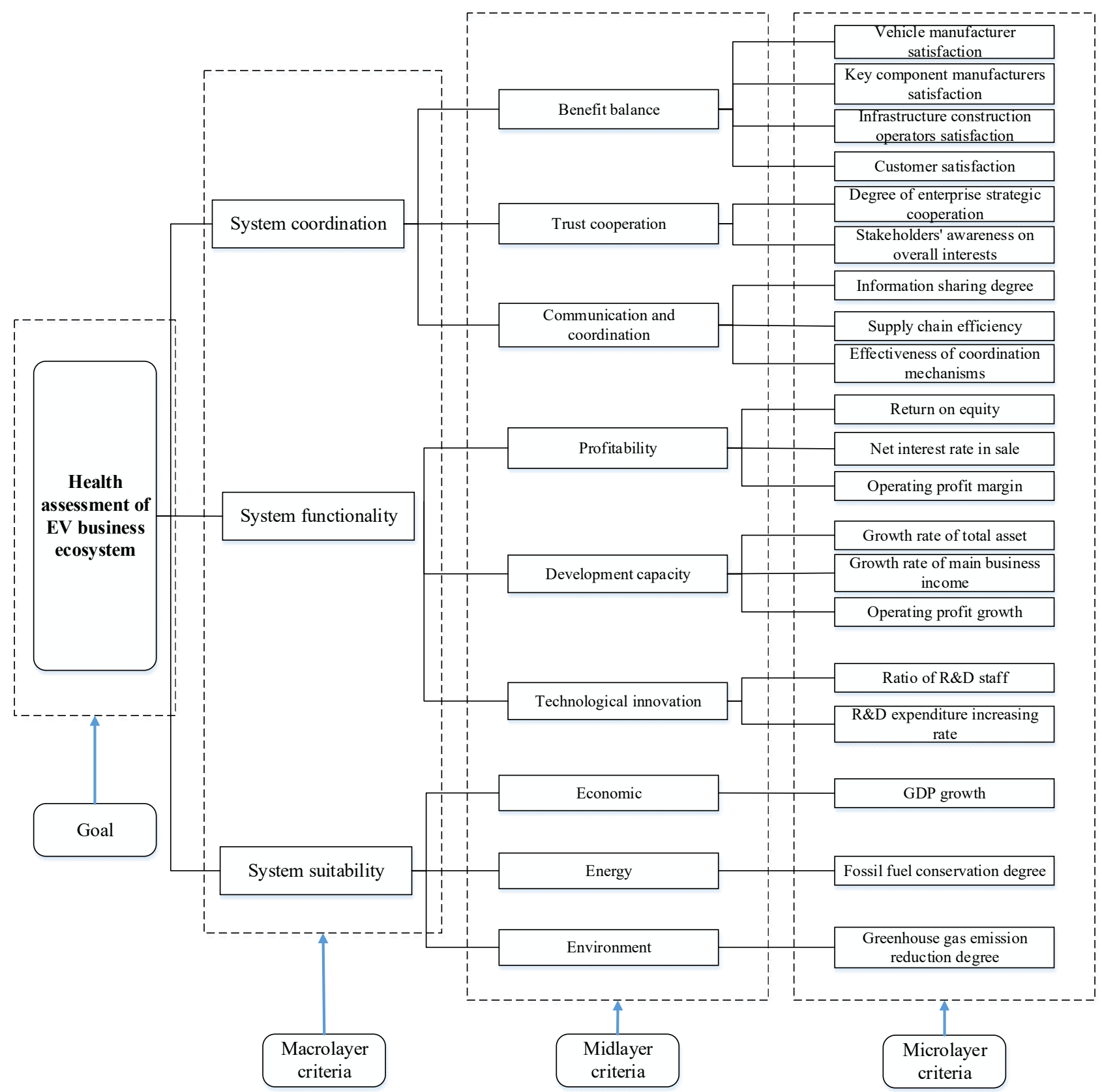

Fig. 1 Health evaluation index system of EV business ecosystem

System Coordination. System coordination is to measure the rationality of the system structure, and the effectiveness of the operation mechanism from the perspective of the relationship between stakeholders.

(1)Benefit balance

Benefit balance mainly reflects the distribution mechanism among the members of the system, the evaluation indicators include vehicle manufacturer satisfaction $\left(\mathrm{X}_{1}\right)$, key component manufacturers satisfaction $\left(\mathrm{X}_{2}\right)$, infrastructure construction operators satisfaction $\left(\mathrm{X}_{3}\right)$ and customer satisfaction $\left(\mathrm{X}_{4}\right)$.

(2)Trust cooperation

Trust cooperation is employed to judge the trust and cooperation mechanism among system members, the evaluation indicators include degree of enterprise strategic cooperation $\left(\mathrm{X}_{5}\right)$ and stakeholders' awareness on overall interests $\left(\mathrm{X}_{6}\right)$.

(3)Communication and coordination

The element of communication and coordination reflexes the communication effectiveness and coordination efficiency among the members of the system, the evaluation indicators include 
information sharing degree $\left(\mathrm{X}_{7}\right)$, supply chain efficiency $\left(\mathrm{X}_{8}\right)$ and effectiveness of coordination mechanisms $\left(\mathrm{X}_{9}\right)$.

System Functionality. System functionality is to analyze the profitability, development capacity and technological innovation from the perspective of the overall operation of the system.

(1) Profitability

Profitability generally refers to the ability of an enterprise to obtain profits and is measured by the following indicators:

Return on equity $\left(\mathrm{X}_{10}\right)$ : It is the most representative indicator to reflect the level of earnings of equity capital as it intuitively demonstrates the effectiveness of investors' capital input.

$$
\text { Return on equity }=\frac{\text { Net profit }}{\text { Average net assets }} \times 100 \%
$$

Net interest rate in sale (X11): Measure the ability of an enterprise to obtain sales revenue for a given period of time.

Net interest rate in sale $=\frac{\text { Net profit }}{\text { Sales revenue }} \times 100 \%$

Operating profit margin (X12): Measure the operating efficiency of enterprises and reflects the ability of business managers to obtain profits through consideration of operating costs.

Operating profit margin $=\frac{\text { Operating profit }}{\text { Operating income }} \times 100 \%$

(2) Development capacity

Development capacity refers to the potential ability of enterprises to expand their scale and strength, which is usually measured by the following indicators:

Growth rate of total asset $\left(\mathrm{X}_{13}\right)$ : Reflect the growth rate of enterprises and measure their development ability from the growth of total assets.

Growth rate of total asset $=\frac{\text { Total assets growth this year }}{\text { Total assets last year }} \times 100 \%$

Growth rate of main business income $\left(\mathrm{X}_{14}\right)$ : The main business refers to the core business of the system, which reflects the expansion of the main business income and market development capabilities.

Growth rate of main business income $=\frac{\text { Growth of main business revenue this year }}{\text { business revenue last year }} \times 100 \%$

Operating profit growth $\left(\mathrm{X}_{15}\right)$ : Reflect the ability to create profits continuously of the system's key business.

Operating profit growth $=\frac{\text { Growth in operating profit this year }}{\text { Operating profit last year }} \times 100 \%$

(3) Technological innovation

Technological innovation capability has a direct impact on the functioning of the business ecosystem, which is usually measured by the following indicators:

Ratio of $\mathrm{R} \& \mathrm{D}$ staff $\left(\mathrm{X}_{16}\right)$ : When the number of researchers in lager, the $\mathrm{R} \& \mathrm{D}$ capability is stronger and it is easier obtain core competence. Therefore, the indicator as ratio of R\&D staff can be used to evaluate the R \& D capability.

$$
\text { Ratio of } R \& D \text { staff }=\frac{R \& D \text { staff }}{\text { Total number of employees }} \times 100 \%
$$

$\mathrm{R} \& \mathrm{D}$ expenditure increasing rate $\left(\mathrm{X}_{17}\right)$ : Reflect the enterprises' emphasis on scientific research. Electric vehicles are emerging industries that require scientific and technological support.

$R \& D$ expenditure increasing rate $=\frac{\text { The increase } R \& D \text { fees this year }}{R \& D \text { fees this year }} \times 100 \%$ 
System Suitability. System suitability reflect the adaptability of the system to external factors. Important external factors that affects the system include the economy, energy, environment and so on. The external factors put forward the development goal of the system, and constitute the restriction and condition of the ecosystem development. External factors and systems interact with each other and depend on each other.

(1) Economic

The level of economic development will directly determine the growth rate and regional distribution of the electric vehicle demand, and affect the development space of the system members, which can be measured by the GDP growth (X18).

(2) Energy

Energy factors like the total amount, layout and structure of energy resources provide the material basis for development of the system members. At the same time, it also set a goal and constraint condition for the system development, which is primarily measured by fossil fuel conservation degree (X19).

(3) Environment

Environmental factors provide space for the survival and development of the business ecosystem, conversely, the behavior of system members will also change the environment. The impacts which conducted by the EV business ecosystem can be measured by greenhouse gas emission reduction degree $(\mathrm{X} 20)$.

\section{Health evaluation based on Projection Pursuit and improved TOPSIS Method}

\section{Method and Methodology.}

Projection Pursuit. Projection pursuit (PP) is a kind of technique to conduct exploratory data analysis among multivariate data. The essence of the model is projecting high-dimensional data onto a low-dimensional space via a projection index. Based on the low-dimensional space, it is possible to get the optimal projection direction by maximizing the projection index that describes the inhomogeneity of data. The virtue of PP to analyze data structures in low dimensional space while well reflecting the characteristics of high-dimensional data structure. From this point of view, this paper employs PP to determine the contribution of each evaluation indicator, and the steps are as follows:

Step 1: Normalizing the indicator of each sample data.

In order to resolve the problem of comparability among indicators, it is necessary to choose a proper method to eliminate the dimension.

For positive indicators:

$x^{*}(i, j)=\frac{x(i, j)-x_{\min }(j)}{x_{\max }(j)-x_{\min }(j)}$

For negative indicators:

$x^{*}(i, j)=\frac{x_{\max }(j)-x(i, j)}{x_{\max }(j)-x_{\min }(j)}$

where $x_{\max }(j), x_{\min }(j)$ are the maximum and minimum of the index $j$, respectively.

Step 2: Constructing the projection index function $f(w)$.

The projection pursuit model is to synthesize the $m$ dimensional data $x_{i j}$ into a one-dimensional projection value $z_{i}$ in the projection direction of $w_{j}=[w(1), w(2), \cdots, w(m)]$.

$z(i)=\sum_{j=1}^{n} w(j) x^{*}(i, j), i=1,2, \mathrm{~L}, n$

Where $w(j)$ is the unit vector, and when synthesizing the projection index value, it is required to extract variation information as far as possible. The scatter characteristics should be as local 
projection points are as dense as possible, and it is best to condense into a number of dots; while on the whole, the projection points and clusters are scattered as far as possible, so the projection index function can be expressed as:

$$
f(w)=S_{z} D_{z}
$$

where $S_{z}$ is the standard deviation of the project value $z(i), D_{z}$ is the local density of the project value $z(i)$.

$$
\begin{aligned}
& S_{z}=\sqrt{\frac{\sum_{i=1}^{n}[z(i)-E(z)]^{2}}{n-1}} \\
& D_{z}=\sum_{i=1}^{n} \sum_{j=1}^{n}\left(R-r_{i j}\right) U\left(R-r_{i j}\right)
\end{aligned}
$$

Where $E(z)$ is the mean value of sequence $\{z(i)\} . R$ is the window radius of the local density, which was generally preferable to $0.1 S_{z} . r_{i j}$ is the distance between samples, $r_{i j}=|z(i)-z(j)| . U(h)$ is unit step function, when $R<r_{i j}, U\left(R-r_{i j}\right)=0$; when $R \geq r_{i j}, U\left(R-r_{i j}\right)=1$.

Step 3: Optimizing the projection index function.

When the index value is given, the projection index function $f(w)$ only changes with the projection direction $w$. Different $w$ represents various characteristics of the data structure. The best projection direction, referring the direction that can exposes the characteristic structure of high dimensional data to the greatest extent possible, can be computed through solving the maximization problem of projection index function.

The objective function:

$\operatorname{Max}: f(w)=S_{z} D_{z}$

The constraints:

$\sum_{j}^{m} w^{2}(j)=1$

This is a complex nonlinear optimization problem that takes $\{w(j) \mid j=1,2, \ldots m\}$ as optimization variable. This paper adopts firefly algorithm (FA) to optimize the objective function.

FA, the latest algorithm among swarm intelligence optimization algorithm, was first proposed by Yang [31] according to the characteristics of the firefly. The flow of the FA is shown as follows:

(1) Initializing the basic parameters. Set the number of fireflies $m$, light intensity $\gamma$, the maximum attractiveness $\beta_{0}$, step length factor $\alpha$, searching precision $\varepsilon$ or the maximum iterations $N$.

(2) Initializing the location of the firefly randomly and calculating the target function value of the firefly as the maximum brightness $I_{0}$ respectively.

(3) The relative brightness $I$ and the attractiveness $\beta$ of the firefly in the population are calculated. Then the movement direction of the firefly is determined according to the relative brightness.

(4) Updating the spatial position of the firefly. A random perturbation is conducted on the firefly in the optimum position. Recalculating the brightness of the firefly on the basis of the updated location.

(5) When the searching precision meets the requirements or reaches the maximum iterations, turn to (6); otherwise, increase iterations by 1 and turn to (4) as proceeding to the next searching.

(6) Outputting the global extreme points and optimal individual values.

Matter-element Extension Combined with TOPSIS. Matter-element extension analysis is proved to be a suitable method to solve contradictory problems in multi-factor assessment $[32,33]$. The idea of matter-element evaluation is that, to begin with, divide objects into several grades according to existing data and the ranges of data at all levels are given by database or expert opinions. Then induce 
the indicators of evaluation objects into the set of each grade assesse for multi-index evaluation. The results are compared according to the value of the correlation function. The greater the degree of correlation is, the better the degree of coincidence is.

The reliability of traditional matter-element analysis mainly depends on whether the classical domain and joint domain settings are reasonable. When the classical domain settings is not reasonable, it will lead to evaluation objects in the same grade and can only get partial order sorting. In order to overcome this problem, this paper adopts an improved matter-element extension analysis combined with TOPSIS [34].

Technique for order preference by similarity to ideal solution (TOPSIS) is a multi-objective decision analysis method. The main idea is to calculate positive and negative ideal solution which refer to the optimal scheme and the worst scheme in the finite evaluation schemes. The optimal scheme means each indicator value is the best of all the alternatives; contrarily, the worst scheme means each indicator value is the worst of all the alternatives. In order to obtain the relative closeness degree, the distance between the object and the positive and negative ideal solution is calculated respectively. Generally, the relative closeness is the principle to judge the merits and demerits of the schemes. The scheme which is close to the positive ideal solution and far from the negative will be the best one among all schemes.

The basic thinking of matter-element extension combined with TOPSIS is: TOPSIS is used to build up the positive and negative ideal solutions. In the light of assessment need, the range of extreme values is divided into $N$ equal parts, and corresponding coordination evaluation set to the partition interval is given. Then calculate the the relative closeness between the various indicators and each level to determine which evaluation grade the evaluated object belongs to.

\section{Health Evaluation Model.}

Step 1: Normalizing the original judgment matrix.

In order to resolve the problem of comparability among indicators, it is necessary to choose a proper method to eliminate the dimension. The evaluation indices $n$ of objects $m$ and the original matrix is set up as follows:

$$
X=\left(x_{i j}\right)_{m \times n}=\left[\begin{array}{llll}
x_{11} & x_{12} & \mathrm{~L} & x_{1 n} \\
x_{21} & x_{22} & \mathrm{~L} & x_{2 n} \\
\mathrm{~L} & \mathrm{~L} & \mathrm{~L} & \mathrm{~L} \\
x_{m 1} & x_{m 2} & \mathrm{~L} & x_{m n}
\end{array}\right]
$$

The following normalization arithmetic can convert the original judgment matrix $X$ into a standard matrix $Z=\left(z_{i j}\right)_{m \times n}$.

$y_{i j}= \begin{cases}x_{i j} & \text { positive indicator } \\ -x_{i j} & \text { negative indicator }\end{cases}$

The non-dimensional processing is:

$$
z_{i j}=\frac{y_{i j}}{\left(\sum_{i=1}^{m} y_{i j}^{2}\right)^{\frac{1}{2}}}
$$

Step 2: Determining the weight of each indicator.

The projection index function is constructed and optimized through FA to get the best projection direction, which is the index weight. The concrete steps are shown in section 4.1.1.

Step 3: Setting up the weighted standardization decision matrix. 


$$
U_{i j}=\left[\begin{array}{cccc}
u_{11} & u_{12} & \mathrm{~L} & u_{1 n} \\
u_{21} & u_{22} & \mathrm{~L} & u_{2 n} \\
\mathrm{~L} & \mathrm{~L} & \mathrm{~L} & \mathrm{~L} \\
u_{m 1} & u_{m 2} & \mathrm{~L} & u_{m n}
\end{array}\right]=\left[\begin{array}{cccc}
w_{1} z_{11} & w_{2} z_{12} & \mathrm{~L} & w_{n} z_{1 n} \\
w_{1} z_{21} & w_{2} z_{22} & \mathrm{~L} & w_{n} z_{2 n} \\
\mathrm{~L} & \mathrm{~L} & \mathrm{~L} & \mathrm{~L} \\
w_{1} z_{m 1} & w_{2} z_{m 2} & \mathrm{~L} & w_{n} z_{m n}
\end{array}\right]
$$

Step 4: Determining the positive and negative ideal solution.

In the weighted standardization decision matrix, the positive ideal point $U^{+}$is the vector of the maximum element of each column when the negative ideal point $U^{-}$is the vector of the minimum element of each column.

$$
\begin{aligned}
& U^{+}=\left(u_{1}^{+}, u_{2}^{+}, \mathrm{L}, u_{m}^{+}\right), u_{j}^{+}=\max \left\{u_{i j}\right\}(j=1,2, \mathrm{~L}, n) \\
& U^{-}=\left(u_{1}^{-}, u_{2}^{-}, \mathrm{L}, u_{m}^{-}\right), u_{j}^{-}=\min \left\{u_{i j}\right\}(j=1,2, \mathrm{~L}, n)
\end{aligned}
$$

Step 5: Partitioning the extreme value interval and calculating the closeness degree.

Dividing the extreme value interval of the positive and negative ideal solutions into $N$ layers, and the range of each layer is $S_{j t}=\left(s_{j t}^{1}, s_{j t}^{2}\right), j=1,2, \mathrm{~L}, n ; t=1,2, \mathrm{~L}, \mathrm{~N}$. The closeness degree of each element with the evaluation interval is as follows:

$$
D\left(N_{i}\right)=\left|z_{i j}-\frac{s_{j t}^{1}+s_{j t}^{2}}{2}\right|
$$

The weighted closeness degree of each evaluation scheme is:

$$
K_{j}\left(N_{i}\right)=1-\sum_{j=1}^{n} w_{j} D\left(N_{i}\right)
$$

Step 6: Calculating the eigenvalues and grading.

In order to further judge which level the evaluated object is closer to, it is necessary to calculate the eigenvalues $\lambda_{i}$.

$$
\begin{aligned}
& \bar{K}_{j}\left(N_{i}\right)=\frac{K_{j}\left(N_{i}\right)-\min K\left(N_{i}\right)}{\max K\left(N_{i}\right)-\min K\left(N_{i}\right)} \\
& \lambda_{i}=\frac{\sum_{j=1}^{m} s \bar{K}_{j}\left(N_{i}\right)}{\sum_{j=1}^{m} \bar{K}_{j}\left(N_{i}\right)}
\end{aligned}
$$

\section{Case Study}

In 2009, the Beijing new energy automotive industry alliance was established which integrated more than 60 companies in this field, including original equipment manufacturers (OEM), traction battery manufacturers, electric motor firms, research institutes, end users and so on. At present, the production capacity is around 50,000 vehicles each year. Foton Motor is a keystone player in the EV business ecosystem, as a central player establishing the industrial alliance of the EV industry in Beijing, it collaborates closely with many other companies and organizations.

In this paper, the health degree of this EV business ecosystem is investigated based on the projection pursuit and matter-element extension combined with TOPSIS considering system coordination, functionality and suitability from 2013 to 2016. The qualitative indicators are quantitated by the panel composed of experts from the marketing department, economic sectors, science and technology development department, environmental protection department and a specialist in the field of electric vehicle and business ecosystem, according to the scoring criteria in Section 3.2. The quantitative date of samples is obtained from the statistics of general accounting department and human resources department. 
Step 1: According to the normalization arithmetic, the standard matrix $Z$ is obtained.

$$
Z=\left[\begin{array}{lllll}
0.4383 & 0.3425 & 0.4695 & \mathrm{~L} & 0.3885 \\
0.3703 & 0.4795 & 0.4559 & \mathrm{~L} & 0.4695 \\
0.5441 & 0.5937 & 0.5103 & \mathrm{~L} & 0.5100 \\
0.6121 & 0.5480 & 0.5580 & \mathrm{~L} & 0.6071
\end{array}\right]
$$

Step 2: Determining the weight coefficient. Based on project pursuit model and FA, the weights $w_{j}$ of the indices are calculated.

$$
\begin{aligned}
w_{j}= & (0.0508,0.0406,0.0658,0.0461,0.0461,0.0454,0.0576,0.0404,0.0454,0.0700, \\
& 0.0479,0.0551,0.0600,0.0412,0.0435,0.0476,0.0607,0.0460,0.0425,0.0474)
\end{aligned}
$$

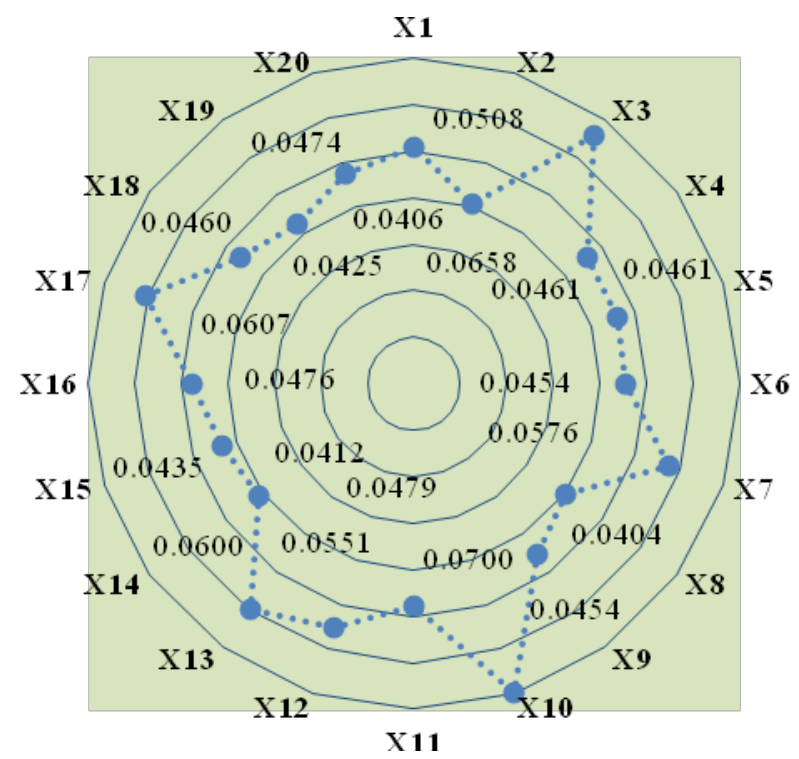

Fig.2 Radar chart of the indicators' impact values

It is well acknowledged that the larger the value of the corresponding index, the greater the degree of effects. The influence degree of each indicator is shown in Figure 2. Obviously, the factor return on equity has the greatest influence over the health of EV ecosystem in Beijing, followed by the infrastructure construction operators satisfaction, $R \& D$ expenditure increasing rate, Growth rate of total asset, information sharing degree, operating profit margin, vehicle manufacturer satisfaction and net interest rate in sale. Meanwhile, it can be noted that customer satisfaction and Degree of enterprise strategic cooperation, effectiveness of coordination mechanisms and stakeholders' awareness on overall interests have the same influence degree respectively. In a word, all these vital factors should be put more attention and focus when improving the healthy development level of the EV ecosystem.

Step 3: Setting up the weighted standardization decision matrix $U$.

$$
U=\left[\begin{array}{lllll}
0.0223 & 0.0139 & 0.0309 & \mathrm{~L} & 0.0184 \\
0.0188 & 0.0195 & 0.0300 & \mathrm{~L} & 0.0223 \\
0.0276 & 0.0241 & 0.0336 & \mathrm{~L} & 0.0242 \\
0.0311 & 0.0222 & 0.0367 & \mathrm{~L} & 0.0288
\end{array}\right]
$$

Step 4: Calculating the positive negative ideal solution based on the weighted standardization decision matrix.

$$
\begin{aligned}
U^{+}= & (0.0311,0.0241,0.0367,0.0265,0.0278,0.0260,0.0319,0.0242,0.0270,0.0474, \\
& 0.0268,0.0293,0.0357,0.0255,0.0244,0.0303,0.0475,0.0244,0.0235,0.0288) \\
U^{-}= & (0.0188,0.0139,0.0300,0.0195,0.0157,0.0180,0.0264,0.0112,0.0168,0.0239, \\
& 0.0211,0.0262,0.0235,0.0132,0.0184,0.0158,0.0146,0.0212,0.0179,0.0184)
\end{aligned}
$$


Step 5: Diving the extreme value range consisting of the positive and negative ideal solution is divided into five grades namely very poor, poor, moderate, good and excellent. Taking the index "vehicle manufacturer satisfaction" as an example, the results of the positive and negative ideal solution are $u^{+}=0.0311$ and $u^{-}=0.0188$ respectively, then it is divided into five classes:

$$
\begin{aligned}
& s_{11}=[0.0188,0.0213] \\
& s_{12}=[0.0213,0.0237] \\
& s_{13}=[0.0237,0.0262] \\
& s_{14}=[0.0262,0.0286] \\
& s_{15}=[0.0286,0.0311]
\end{aligned}
$$

Other extreme ranges are the same as this.

Step 6: Calculating the closeness degree between the weighted decision matrix and the five grades.

$$
\begin{aligned}
D\left(N_{1}\right) & =\left[\begin{array}{lllll}
0.0022 & 0.0010 & 0.0002 & \mathrm{~L} & 0.0010 \\
0.0012 & 0.0045 & 0.0007 & \mathrm{~L} & 0.0028 \\
0.0076 & 0.0092 & 0.0029 & \mathrm{~L} & 0.0047 \\
0.0110 & 0.0073 & 0.0060 & \mathrm{~L} & 0.0093
\end{array}\right] \\
D\left(N_{2}\right) & =\left[\begin{array}{lllll}
0.0002 & 0.0031 & 0.0011 & \mathrm{~L} & 0.0031 \\
0.0037 & 0.0025 & 0.0020 & \mathrm{~L} & 0.0007 \\
0.0051 & 0.0071 & 0.0016 & \mathrm{~L} & 0.0026 \\
0.0086 & 0.0053 & 0.0047 & \mathrm{~L} & 0.0073
\end{array}\right] \\
D\left(N_{3}\right) & =\left[\begin{array}{lllll}
0.0027 & 0.0051 & 0.0025 & \mathrm{~L} & 0.0052 \\
0.0061 & 0.0005 & 0.0034 & \mathrm{~L} & 0.0013 \\
0.0027 & 0.0051 & 0.0002 & \mathrm{~L} & 0.0006 \\
0.0061 & 0.0032 & 0.0034 & \mathrm{~L} & 0.0052
\end{array}\right] \\
D\left(N_{4}\right) & =\left[\begin{array}{lllll}
0.0051 & 0.0071 & 0.0038 & \mathrm{~L} & 0.0073 \\
0.0086 & 0.0016 & 0.0047 & \mathrm{~L} & 0.0034 \\
0.0002 & 0.0031 & 0.0011 & \mathrm{~L} & 0.0015 \\
0.0037 & 0.0012 & 0.0020 & \mathrm{~L} & 0.0031
\end{array}\right] \\
D\left(N_{5}\right)= & {\left[\begin{array}{lllll}
0.0076 & 0.0092 & 0.0051 & \mathrm{~L} & 0.0093 \\
0.0110 & 0.0036 & 0.0060 & \mathrm{~L} & 0.0055 \\
0.0022 & 0.0010 & 0.0025 & \mathrm{~L} & 0.0036 \\
0.0012 & 0.0008 & 0.0007 & \mathrm{~L} & 0.0010
\end{array}\right] }
\end{aligned}
$$

In the light of closeness degree of each element, calculate the weighted closeness degree of each evaluation scheme.

$$
\begin{aligned}
G(2013) & =[0.9989,0.9970,0.9947,0.9925,0.9902] \\
G(2014) & =[0.9977,0.9982,0.9973,0.9953,0.9931] \\
G(2015) & =[0.9934,0.9957,0.9973,0.9976,0.9970] \\
G(2016) & =[0.9905,0.9928,0.9950,0.9972,0.9988]
\end{aligned}
$$

The closeness degree and the characteristic values of the evaluated years were calculated according to Eq.(25) and (26). The results are shown in Table 1. The change of the characteristic value of each year is shown in Figure 3 and the change of the closeness degree of each year is shown in Fig.8. 
Table 1. Health evaluation results

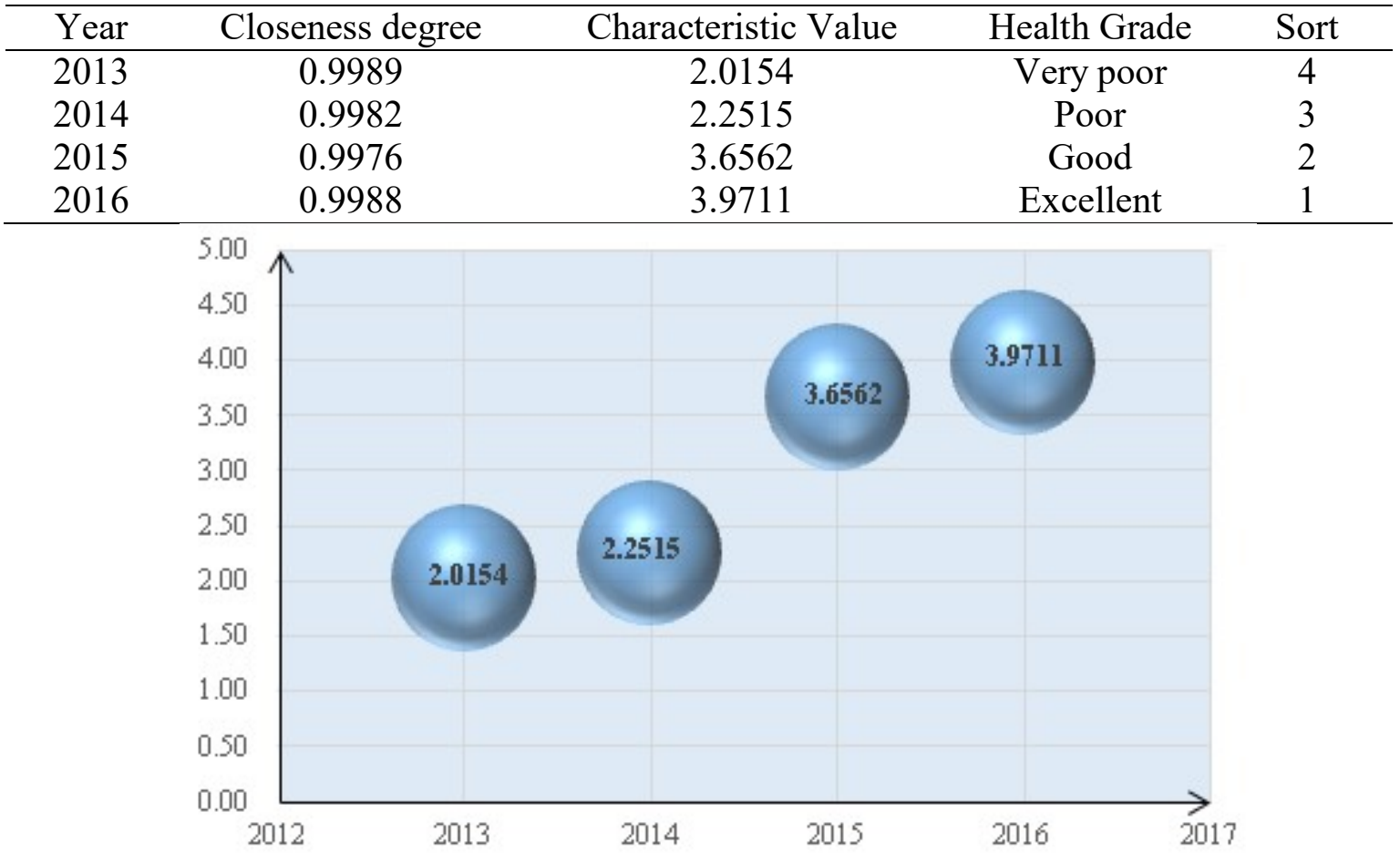

Fig.3 Trend chart of characteristic value during 2013-2016

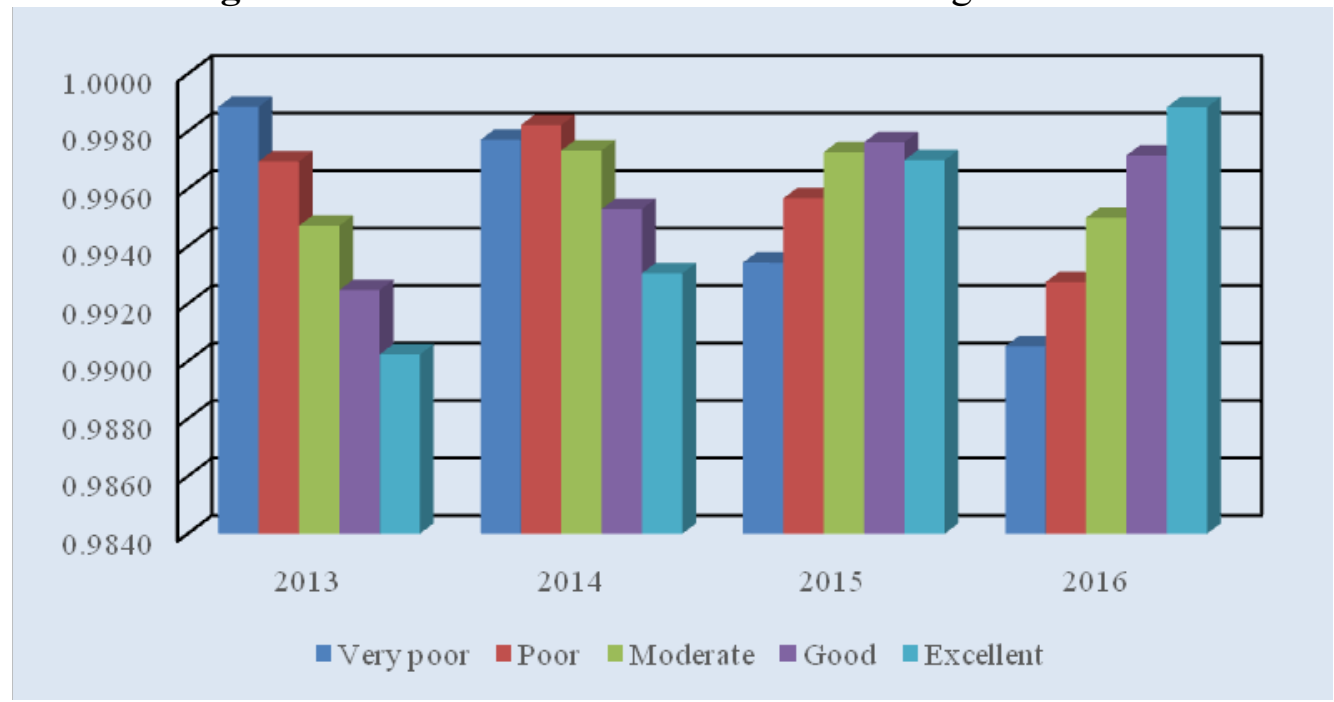

Fig.4 Closeness degree during 2013-2016

According to the principle of maximum membership degree, it can be seen from Figure 6 that overall health status during 2013-2016 is "very poor", "poor", "good" and "excellent" separately. On the other hand, the characteristic value of the EV business ecosystem is $2016>2015>2014>2013$, the greater characteristic value means the evaluated object is closer to the grade. The evaluation indicates that system coordination, system functionality and system suitability of the EV business ecosystem have been all increased year by year since 2013, and the development of various indicators of the system has become more balanced. From the perspective of energy supply, Beijing has formed the pattern which combines electric charging and changing, fast charging and slow charging, concentration and distribution starting in 2013. The Beijing Electric Power company researches and develops intelligent charging equipment. The characteristics of highly automatic and fast switching have solved the bottleneck problem of energy supply, and laid a solid technical foundation for building intelligent charging service network. At the same time, the security operation platform for electric vehicle was built in Beijing, all vehicles are included in the demonstration platform management, which realizes real-time online monitoring and fault processing of EVs as well as 
provides information support and security for the smooth operation. As for operation mode, the EV industry in Beijing mainly adopts the business model of "separation of vehicles and batteries, battery leasing". The infrastructure construction of new energy vehicles in Beijing is relatively late, but it has developed rapidly in recent years. By the end of 2014, Beijing has built 6 large and medium power stations, more than 60 charging stations and nearly 2000 charging piles. Moreover, Beijing Municipal Science and Technology Commission has vigorously promoted the combination of government production, learning and research, providing strong support for the development of electric vehicles in Beijing, thus improving the health level of the EV business ecosystem.

\section{Conclusions}

In the face of the complex dynamic environment, long-term survival and development of enterprises depends on the whole ecosystem and the health condition more and more. Therefore, it is of great significance to evaluate the health condition of business ecosystem objectively and effectively. The health status is influenced by many factors, which adds difficulty to the evaluation work. The assessment results have a lot to do with the evaluation index system and evaluation method. For the former, when constructing index system, it needs from both internal and external aspects of comprehensive consideration. From this point of view, this paper employs a step-by-step procedure to determine the index system of EV business ecosystem health assessment. The index system is set up from system coordination, functionality and suitability. Each perspective is subdivided into several aspects and described by some typical indicators including quantitative and qualitative ones. Finally, the indicator system of EV business ecosystem health assessment is established consisting of these selected indicators. Since the indicator system is constructed based on system characteristics, enabling it describes the health condition objectively to a certain degree. But the index system in this study may not be comprehensive to reflect the business ecosystem that still needs to be improved with more typical indicators in future study.

For the latter, it is necessary to study the methods and models for assessing business ecosystem health. In order to ensure the objectivity of the index weight, projection pursuit optimized by firefly algorithm is used to determine the weight. Then we assessed the health status of the ecosystem in Beijing through an improved matter-element extension combined with TOPSIS. We found that the overall health status during 2013-2016 is "very poor", "poor", "good" and "excellent" separately. Our findings also suggest that the health status is increasing year by year which implies the new business model is more compatible, and is conducive to promoting the EV industry. Our results are proved in accord with the physical truth and realities of the situation, which confirms that it is effective and feasible to evaluate the health condition through the proposed model.

\section{Acknowledgements}

The paper is supported by "National Power Grid Corp headquarter science and technology project(Research on the key technology of the construction and cooperative development of the company's industrial ecosystem)", "Natural Science Foundation of China (Project No. 71471059) ", "the Fundamental Research Funds for the Central Universities (2018ZD14)".

\section{References}

[1] Shang T, Shi Y. The emergence of the electric vehicle industry in Chinese Shandong Province: A research design for understanding business ecosystem capabilities. Journal of Chinese Entrepreneurship, 2013, 5(1): 61-75.

[2] Rong K, Shi Y, Yu J. Nurturing business ecosystems to deal with industry uncertainties. Industrial management \& data systems, 2013, 113(3): 385-402. 
[3] Iansiti M, Levien R. The keystone advantage: what the new dynamics of business ecosystems mean for strategy, innovation, and sustainability. Harvard Business Press, 2004.

[4] Kenney M, Pon B. Structuring the smartphone industry: is the mobile internet OS platform the key?. Journal of Industry, Competition and Trade, 2011, 11(3): 239-261.

[5] Lin J H, Wang M Y. Complementary assets, appropriability, and patent commercialization: Market sensing capability as a moderator. Asia Pacific Management Review, 2015, 20(3): 141-147.

[6] Markus M L, Loebbecke C. Commoditized digital processes and business community platforms: new opportunities and challenges for digital business strategies. Mis Quarterly, 2013, 37(2): 649-654.

[7] Iansiti M, Levien R. The new operational dynamics of business ecosystems: Implications for policy, operations and technology strategy. Boston, MA: Division of Research, Harvard Business School, 2002.

[8] Moore J F. Predators and prey: a new ecology of competition. Harvard business review, 1993, 71(3): 75-83.

[9] Moore J F. The death of competition: leadership and strategy in the age of business ecosystems. Harper Paperbacks, 1997.

[10] Lin T C, Kung S F, Wang H C. Effects of firm size and geographical proximity on different models of interaction between university and firm: A case study. Asia Pacific Management Review, 2015, 20(2): 90-99.

[11] Rammel C, Stagl S, Wilfing H. Managing complex adaptive systems - a co-evolutionary perspective on natural resource management[J]. Ecological economics, 2007, 63(1): 9-21.

[12] Kley F, Lerch C, Dallinger D. New business models for electric cars-A holistic approach[J]. Energy Policy, 2011, 39(6): 3392-3403.

[13] Rong $\mathrm{K}, \mathrm{Hu} \mathrm{G}$, Hou J, et al. Business ecosystem extension: facilitating the technology substitution. International Journal of Technology Management, 2013, 63(3-4): 268-294.

[14] Lu C, Rong K, You J, et al. Business ecosystem and stakeholders' role transformation: Evidence from Chinese emerging electric vehicle industry. Expert Systems with applications, 2014, 41(10): 4579-4595.

[15] Moore J F. Business ecosystems and the view from the firm. The Antitrust Bulletin, 2006, 51(1): $31-75$.

[16] Adner R, Kapoor R. Value creation in innovation ecosystems: How the structure of technological interdependence affects firm performance in new technology generations. Strategic management journal, 2010, 31(3): 306-333.

[17] Kim H, Lee J N, Han J. The role of IT in business ecosystems. Communications of the ACM, 2010, 53(5): 151-156.

[18] Cusumano M A. Platforms and services: Understanding the resurgence of Apple. Communications of the ACM, 2010, 53(10): 22-24.

[19] Wnuk K, Runeson P, Lantz M, et al. Bridges and barriers to hardware-dependent software ecosystem participation-a case study. Information and Software Technology, 2014, 56(11): 1493-1507.

[20] Galateanu E, Avasilcai S. Framing the Competitive Behaviors of Niche Players: The Electric Vehicle Business Ecosystem Perspective. Procedia-Social and Behavioral Sciences, 2016, 221: 342-351. 
[21] Bohnsack R, Pinkse J, Kolk A. Business models for sustainable technologies: Exploring business model evolution in the case of electric vehicles. Research Policy, 2014, 43(2): 284-300.

[22] Rong K, Shi Y, Shang T, et al. Organizing business ecosystems in emerging electric vehicle industry: Structure, mechanism, and integrated configuration. Energy Policy, 2017, 107: 234-247.

[23] den Hartigh E, Tol M, Visscher W. The health measurement of a business ecosystem. Proceedings of the European Network on Chaos and Complexity Research and Management Practice Meeting. 2006: 1-39.

[24] Hu B, Zhang J R, Shao R J, Connotation and evaluation index system of the enterprise ecosystem health. Science and Technology Management Research. 2006, 1: 59-61.

[25] Zhang W H, A study on evaluation method of Business ecosystem health. Modernization of Management. 2007, 5: 40-42.

[26] Li D, Classification research of business ecosystem founding on its evolution features - The clustering analyses of 33 typical core corporations' ecosystem practices. China Industrial Economics. 2008, 11:119-129.

[27] Li X, Jie X, Li Q, et al. Research on the evaluation of business ecosystem health. Proceedings of the Sixth International Conference on Management Science and Engineering Management. Springer London, 2013: 1009-1020.

[28] Zhang Y, Zhong M, Jiang Y. A data-driven quantitative assessment model for taxi industry: the scope of business ecosystem's health[J]. European Transport Research Review, 2017, 9(2): 23.

[29] Zubaryeva A, Thiel C, Zaccarelli N, et al. Spatial multi-criteria assessment of potential lead markets for electrified vehicles in Europe. Transportation Research Part A: Policy and Practice, 2012, 46(9): 1477-1489.

[30] Kalyanaram G, Aung Z Z. Value Added Ecosystem and Customer Experience Enhancement Framework. Kindai Management Review, 2015, 3: 49-62.

[31] Yang X S. Firefly algorithm, stochastic test functions and design optimisation. International Journal of Bio-Inspired Computation, 2010, 2(2): 78-84.

[32] Cai W. Extension theory and its application. Chinese Science Bulletin, 1999, 44(17): 1538-1548.

[33] He Y, Dai A, Zhu J, et al. Risk assessment of urban network planning in china based on the matter-element model and extension analysis. International Journal of Electrical Power \& Energy Systems, 2011, 33(3): 775-782.

[34] Xu X, Niu D, Qiu J, et al. Comprehensive evaluation of coordination development for regional power grid and renewable energy power supply based on improved matter element extension and TOPSIS method for sustainability. Sustainability, 2016, 8(2): 143. 